\title{
Warren-Spring based model for the shear yield locus of cohesive biomass powders
}

\author{
Clément Vanneste-Ibarcq ${ }^{1, *}$, Thierry Melkior ${ }^{1}$, Alain de Ryck ${ }^{2}$ \\ ${ }^{1}$ CEA-LITEN, laboratoire de préparation des bioressources, 17 rue des martyrs 38054 Grenoble Cedex 9, France \\ ${ }^{2}$ Centre RAPSODEE, UMR CNRS 2392, Ecole des Mines d'Albi, 81013 Albi CT Cedex 09, France
}

\begin{abstract}
The objectives of this work are to determine accurately the cohesion of biomass powders from simple measures and to propose a new method for the description of the yield locus of powders with easy to measure parameters. The cohesion of 32 powders (wood, other biomasses and inorganic powders) have been analysed with two methods. The first method is the determination of the yield locus from shear tests at $3 \mathrm{kPa}$, performed with a powder rheometer, which gives an access to parameters such as cohesion ( $\mathrm{Y}$ intercept) and traction (X-intercept). The second method is the measurement of avalanche angles in a rotating drum. A linear relation is found between this angle and the cohesion length, ratio of the cohesion derived from the yield locus and the aerated density. Finally, a model is proposed for the prediction of the cohesion and the yield locus at $3 \mathrm{kPa}$, using only 2 parameters easy to measure: the avalanche angle and the aerated density.
\end{abstract}

\section{Introduction}

Energy from biomass should replace in the future a part of the energy we consume. Some biomass conversion technologies, such as biomass gasification, require the biomass to be finely ground. However, biomass powders are cohesive powders. They may present flow issues (consolidation and arching in hoppers for example) [1].

Thus, the design of the process units has to be made cautiously in order to avoid flowing issues. A way to characterize the flowing properties of powders under stress is the yield locus, deduced from the shear test. Important parameters can be derived from this test, such as the unconfined yield stress (representative of the arching tendency of a powder).

In the method of silo design proposed by Jenike [2], the yield locus is fitted with a straight line according to the Mohr-Coulomb failure criterion:

$$
\tau=\mu \sigma+C
$$

$\tau$ : Shear stress $(\mathrm{Pa})$

$\mu$ : coefficient of static friction (-)

$\sigma:$ Normal stress $(\mathrm{Pa})$

$\mathrm{C}$ : Cohesion $(\mathrm{Pa})$

However, cohesive powders exhibit curved yield loci towards lower shear stresses [3] that cannot be described with this model.

Several models for the description of curved yield loci have been proposed $[4,5,6]$. The Warren-Spring equation [3] is commonly used with cohesive powders:

$$
(\tau / C)^{\mathrm{n}}=\frac{\sigma+\mathrm{T}}{\mathrm{T}}
$$

$\tau:$ Shear stress $(\mathrm{Pa})$

$\mathrm{C}$ : Cohesion $(\mathrm{Pa})$

$\mathrm{n}$ : Warren-Spring Index (-)

$\sigma$ : Normal stress $(\mathrm{Pa})$

$\mathrm{T}$ : Tensile stress $(\mathrm{Pa})$

The Warren Spring equation presents three unknowns: $\mathrm{C}, \mathrm{T}$ and $\mathrm{n}$ (with $1<\mathrm{n}<2$ ). Then it cannot be used directly, as different sets of parameters can fit the data. To reduce the number of degrees of freedom, a parameter has to be set. In the work reported by Ashton et al. [3], where the Warren-Spring model has been proposed, the authors measure separately the tensile stress with a tensile test. However, this implies the use of an external experiment, and the hypothesis that the measured tensile stress corresponds to the yield locus tensile stress.

Measuring the avalanche angle in a rotating drum is another way to characterize the flowing properties of powders, under low stresses. The angle of avalanche is defined as the angle to the horizontal of the free surface formed in a slowly rotating drum [1]. A powder showing a high avalanche angle will have a worse flowability than a powder with a low angle. This measure is easy to set up. It is a constant for given setup and method. It is mostly used to compare the flowability of powders. It is not linked yet to powder properties.

The objectives of this study are:

\footnotetext{
* Corresponding author: clement.vanneste-ibarcq@,cea.fr
} 
- To be able to determine the cohesion of a biomass powder from simple measures (density, avalanche angle...).

- To propose a new method for the determination of the yield locus of powders with easy to measure parameters.

\section{Materials and methods}

\subsection{Materials}

In this work, thirty-two powders have been characterised. Twenty-two are wood powders (deciduous and resinous trees). These powders are obtained by drying and grinding (with different mills) wood chips. Six are other biomass powders: industrial sugar, wheat semolina (two grain sizes), grape grounds and two microalgae (dried and ground). Four are inorganic powders: talcum from Fisher Chemicals, beach sand, olivine and alumina.

\subsection{Methods}

\subsubsection{Shear testing}

The yield locus of the powders is measured using a FT4 powder rheometer (Freeman tech), an automated torsional shear tester. The main advantage of this tester is that the powder is aerated with a propeller before the test. Thus, the powder is conditioned, and the results do not depend on the operator manipulations.

The powder is filled in an $85 \mathrm{~mL}$ vessel, aerated with the propeller and consolidated with a piston to $3 \mathrm{kPa}$. Then the vessel is split (the top layer of the powder is removed, the surface is flat). Finally, the shear cell is placed on the top of the powder sample, which is consolidated and then sheared until it yields for different normal stresses.

The yield loci are measured at preconsolidation stress of $3 \mathrm{kPa}$. Twelve points are measured, the normal stresses applied go from $2.5 \mathrm{kPa}$ down to $0.05 \mathrm{kPa}(2.5$, $2,1.75,1.25,1,0.8,0.5,0.3,0.1,0.05,0.01$. The last one is never reached). The shear stress corresponding to the yield of the powder at each normal stress is the yield locus.

\subsubsection{Aerated density}

The aerated density is measured with the FT4. The powder sample is placed in the $42.5 \mathrm{~mL}$ vessel and aerated with the propeller. The vessel is then split (the exact volume of the sample is known) and weighed.

\subsubsection{Avalanche angle}

The avalanche angle is measured with the Revolution Powder analyser from Mercury Scientific Inc. It consists in a see-through cylindrical drum $(10 \mathrm{~cm}$ diameter, $3.3 \mathrm{~cm}$ length). $79 \mathrm{~mL}$ of powder are introduced into the drum, then placed in the analyser. The drum rotates at $0.6 \mathrm{rpm}$ and a camera records the movements of the powder in the drum. The avalanche angle is measured by a software. It is the angle of the top part of the L-shaped surface of the powder before it collapses due to the rotation of the drum. 150 avalanches are recorded. The chosen avalanche angle is the median of the angle distribution.

\section{Results and discussions}

\subsection{Shear test}

An example of yield locus of a wood powder (oak, $\mathrm{d}_{50}=$ $22 \mu \mathrm{m})$ at $3 \mathrm{kPa}$ is given in the figure 1 . The curvature of the locus is obvious.

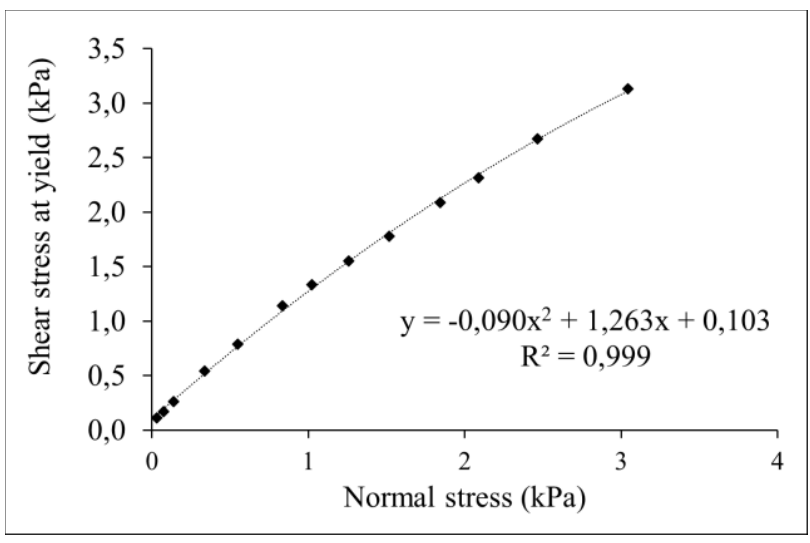

Fig. 1. Yield locus of a wood powder.

The cohesion $\mathrm{C}$ is the $\mathrm{Y}$-intercept of the yield locus. The traction $\mathrm{T}$ is the $\mathrm{X}$-intercept.

To avoid the use of an additional experiment to measure $\mathrm{C}$ or $\mathrm{T}$ (as proposed in the work of Ashton et al.), the data obtained from the shear test are fitted with a second order polynomial. Indeed, this equation fits correctly the data. The Y-intercept of the polynomial is considered as the cohesion $\mathrm{C}$.

The parameters $\mathrm{T}$ and $\mathrm{n}$ are determined by fitting the Warren-Spring equation to experimental data, with the method of least squares (with the condition $1<\mathrm{n}<2$ ).

A relation has been found between $\mathrm{C}$ and $\mathrm{T}$ using this method as shown in the figure 2 . This relation enables to get rid of the unknown $\mathrm{T}$, but requires the aerated density of the powders to be measured. However the density is easier to determine than the tensile stress. 


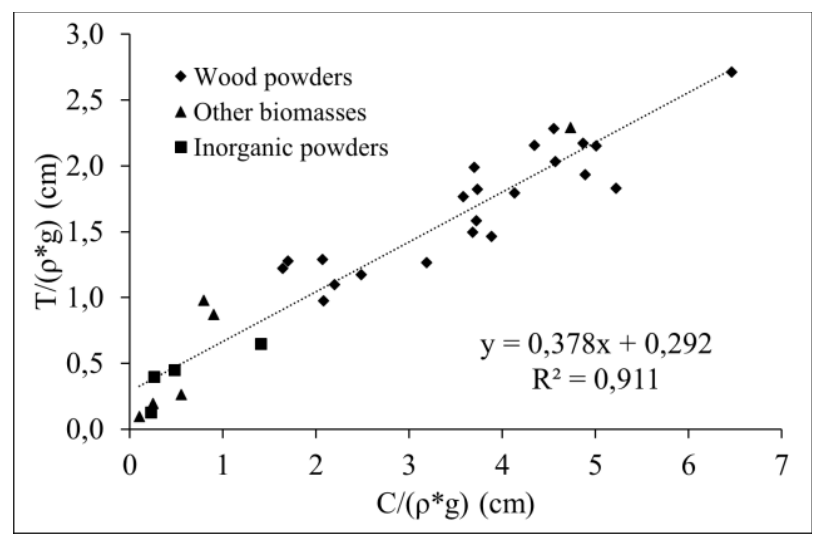

Fig. 2. Relationship between cohesion length and traction length for 32 different powders.

The relation between $\mathrm{T}$ and $\mathrm{C}$ can be written as follows:

$$
\mathrm{T}=\mathrm{aC}+\mathrm{b} \rho \mathrm{g}
$$

$\mathrm{C}$ : Cohesion $(\mathrm{Pa})$

$\mathrm{T}$ : Tensile stress $(\mathrm{Pa})$

$\rho$ : Powder aerated density $\left(\mathrm{kg} / \mathrm{m}^{3}\right)$

$\mathrm{g}$ : Acceleration of gravity $\left(\mathrm{m} / \mathrm{s}^{2}\right)$

a: Constant (-)

b: Constant $(\mathrm{m})$

With $\mathrm{a}=0.378, \mathrm{~b}=2.92 \mathrm{~mm}, \mathrm{R}^{2}=0.911$ at $3 \mathrm{kPa}$

Thus, $\mathrm{T}$ is a function of $\mathrm{C}$ and the density of the powder. This relation is then combined with (1) and the following equation is obtained:

$$
(\tau / C)^{\mathrm{n}}=\frac{\sigma}{\mathrm{aC}+\mathrm{b} \rho \mathrm{g}}+1
$$

This equation has two unknowns, $\mathrm{C}$ and $\mathrm{n}$. The loci are correctly described by equation (4), as presented in the figure 3 for a wood powder (oak, $\mathrm{d}_{50}=22 \mu \mathrm{m}$ ).

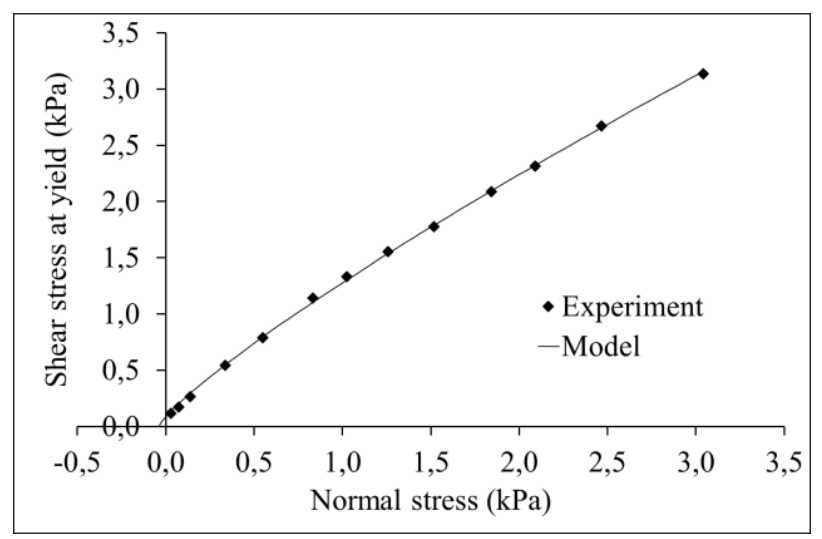

Fig. 3. Yield locus of a wood powder preconsolidated at $3 \mathrm{kPa}$, experimental data and model.

\subsection{Avalanche angle}

\subsubsection{Relationship between the avalanche angle and the cohesion length}

The avalanche angle, cohesion at $3 \mathrm{kPa}$ consolidation and aerated density are measured for each of the 32 powders. The avalanche angle is then plotted versus 1 (see figure 4):

$$
1=\frac{\mathrm{C}}{\rho g}
$$
1: Cohesion length $(\mathrm{m})$
$\mathrm{C}$ : Cohesion at $3 \mathrm{kPa}(\mathrm{Pa})$
$\rho$ : aerated density $\left(\mathrm{kg} / \mathrm{m}^{3}\right)$
g: Acceleration of gravity $\left(\mathrm{m} / \mathrm{s}^{2}\right)$

This length estimates the influence of the cohesive forces acting within the powder over the weight. The larger it is, the greater are the cohesive forces compared to the weight. Figure 4 shows a linear relationship between the avalanche angle and the cohesion length.

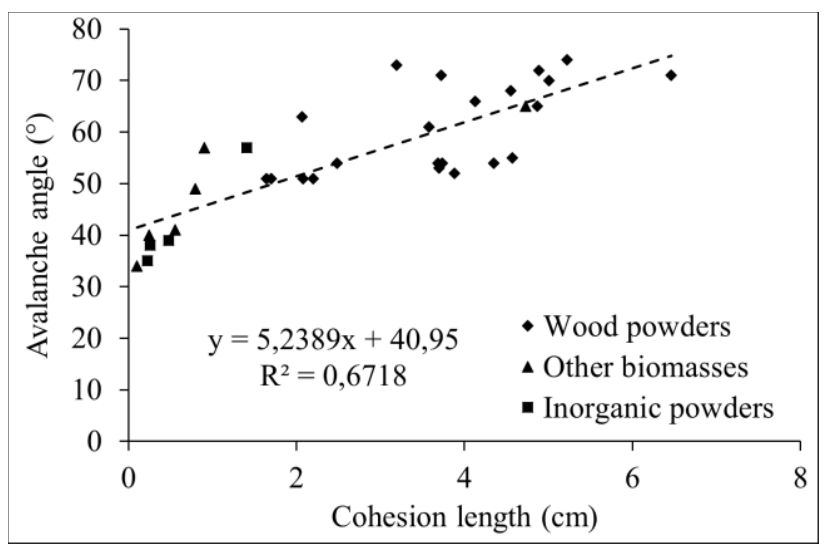

Fig. 4. Relationship between the angle of avalanche and the cohesion length for the 32 powders.

Thus, it is possible to approximate the cohesion of a powder by measuring its avalanche angle and aerated density using the following relation:

$$
\text { Angle }=\alpha 1+\beta
$$

Angle: Avalanche angle $\left({ }^{\circ}\right)$
$\alpha$ : Constant $(\% / \mathrm{cm})$
1 : Cohesion length $(\mathrm{cm})$
$\beta$ : constant $\left(^{\circ}\right)$

With $\alpha=5.24, \beta=40.95, \mathrm{R}^{2}=0.672$

The relative gap between the measured and calculated cohesions are presented in the figure 5 . 


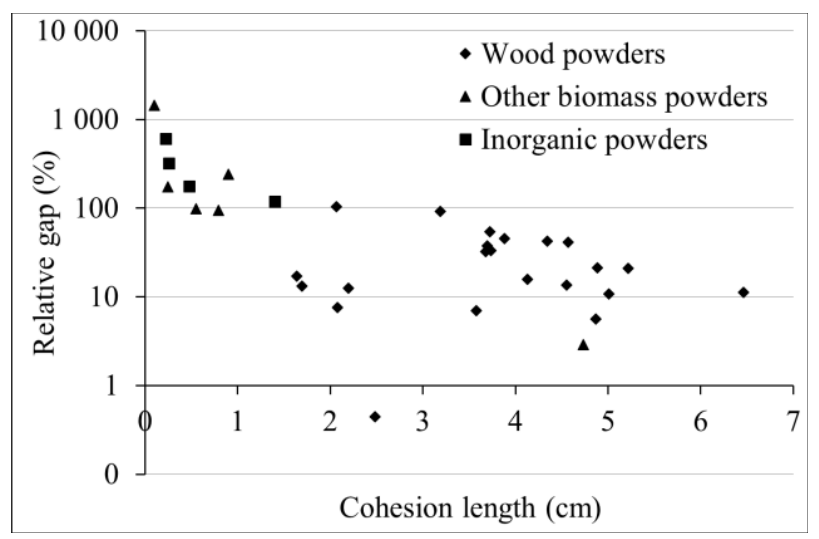

Fig. 5. Relative gap between measured and calculated cohesions as a function of the cohesion length, for the 32 considered powders

For small cohesion lengths $(<1.5 \mathrm{~cm})$, the cohesions are small and the error on the calculated cohesion is therefore large. However, for larger cohesion length $(>1.5 \mathrm{~cm})$, the relation gives an acceptable approximation of the cohesion. Then, to use this relation, the cohesion length must be larger than $1.5 \mathrm{~cm}$, which corresponds to an avalanche angle higher than $50^{\circ}$ (using equation 7).

\subsubsection{Link with the shear test}

The equations found in the previous parts can be used to develop a model for the description of the yield locus.

The Warren-Spring equation has three parameters. C and $\mathrm{T}$ have been expressed with easy to measure parameters (aerated density and avalanche angle). The last parameters $\mathrm{n}$ has to be expressed as well.

For all the powders with $1>1.5 \mathrm{~cm}$, the preconsolidation normal stress is in average $\sigma_{p}=3050 \mathrm{~Pa}$ (0.02 $\mathrm{kPa}$ standard deviation) and the shear stress is approximately constant with $\tau_{\mathrm{p}}=3050 \mathrm{~Pa}(0.13 \mathrm{kPa}$ standard deviation). Thus it is admissible to consider:

$$
\mathrm{n}=\frac{\ln \left(\sigma_{\mathrm{p}} / \mathrm{T}+1\right)}{\ln \left(\tau_{\mathrm{p}} / \mathrm{C}\right)}
$$

By combining the Warren-Spring equation (2) with equations (3), (6) and (7), measuring the avalanche angle and the density of a powder is enough to model its yield locus. An example is presented in the figure 6 for a wood powder. This model is forced to go through the point $(3.05 ; 3.05)$. Then it does not reach the highest points if the preconsolidation point is not exactly $(3.05 ; 3.05)$. However, the lowest stresses are well described.

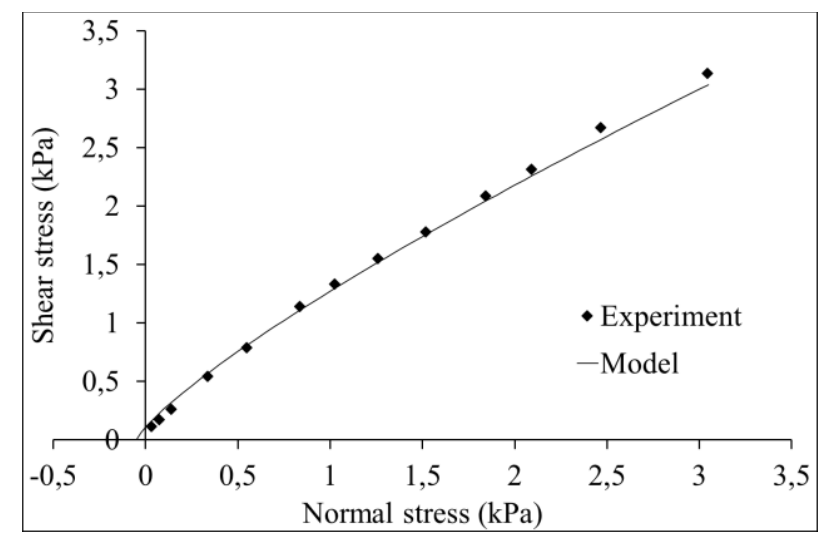

Fig. 6. Yield locus of a wood powder: experiment and model.

\section{Conclusions}

Based on the study of 32 powders, mainly made of wood:

- An approximation equation (4) of the yield locus has been proposed, based on the Warren-Spring model. The proposed model has two unknowns, $\mathrm{C}$ and $\mathrm{n}$, with a condition on $\mathrm{n}$. These parameters can be determined by fitting.

- A linear relation (6) between the avalanche angle, the cohesion and the aerated density of powders is proposed.

- For cohesive biomass powders with an avalanche angle higher than $50^{\circ}$, the yield locus at $3 \mathrm{kPa}$ preconsolidation can be modelled by measuring their aerated density and avalanche angle. These parameters are easier to obtain than a yield locus.

This work has highlighted a way to determine the cohesion and the yield locus of cohesive biomass powders from parameters which are easy to measure (aerated density and avalanche angle). It enables to compare the cohesions and flowability of powders in the situation of a confined flow, typically the discharge of a silo.

\section{References}

1. H. G. Merkus, G. M. H. Meesters, Production, Handling and Characterization of Particulate Materials (Springer, 2015)

2. A. W. Jenike, Storage and Flow of Solids (University of Utah, 1964)

3. M. D. Ashton, D. C.-H. Cheng, R. Farley, F. H. H. Valentin, Rheol. Acta 4, 3 (1965)

4. M. Hirota, K. Takenaka, K. Iimura, M. Suzuki, $A d v$. Powder Technol. 18, 3 (2007)

5. J. L. Amorós, G. Mallol, C. Feliu, M. J. Orts, Chem. Eng. Sci. 66, 18 (2011)

6. J.-M. Geoffroy, J. T. Carstensen, Powder Technol. 76, 2 (1993) 